\title{
The Communications Predicament in Canadian Forestry
}

by

\author{
P.J.B. Duffy ${ }^{2}$ and P.J. Murphy ${ }^{3}$
}

\begin{abstract}
The Canadian forestry enterprise is very large with extensive linkages between resource management, law, industry, labor, trade and the public - all under government regulation. Because the linkages are numerous and poorly understood, few parties have the skill, energy, and mandate to study, understand and act on national issues. Thus issues are not researched with options and solutions raised in a timely way contributing to concerted action in pursuit of goals. Two solutions to this predicament are proposed, the development of a Canadian forestry network and the application of communication technology for multiparty information exchange, including computer conferencing. These two approaches are interrelated and are sufficiently well advanced in Canada to warrant close attention.
\end{abstract}

\section{Résumé}

La foresterie canadienne est une institution gigantesque qui pousse des ramifications très longues et toutes réglementées vers l'aménagement des ressources, le droit, l'industrie, les syndicats, le commerce et le public. Comme ces ramifications sont nombreuses et pas toujours bien connues, peu de personnes ont les compétences, l'énergie ou les attributions qui leurs permettraient d'étudier et de comprendre les problèmes d'envergure nationale et de s'y attaquer. Comme on ne cherche ni ne trouve rapidement les diverses solutions à ces problèmes, la fixation des buts manque de cohésion. A cet état de choses, on propose deux solutions: la mise en place d'un réseau forestier canadien et l'application des techniques de communication pour l'échange de renseignements entre les nombreux intéressés, y compris le recours à la téléconférence informatisée. Ces deux moyens s'épaulent et sont suffisamment perfectionnés au Canada pour qu'on les examinent attentivement.

\section{Introduction}

Present day activity in Canadian forestry matters is characterized by a degree of uncertainty - uncertainty that demands communication as a means for rapid readjustment and appropriate responses.

For instance, industrial commercial interests develop market forecasts and identify opportunities against a constantly changing backdrop of costs, profit margins, competition from new product lines, regulatory changes and other factors. In terms of wood supply, the forest land area is being altered, sometimes reduced, at the local, regional, provincial and national levels, and in a manner that is difficult to measure, record, collate and summarize for resource managers and decision-makers, let alone local governments, public interest groups, and the media. In the area of multiple use of forest lands and resources, a number of competing stakeholders are firming their claim on shared-use for

'Paper given at the Annual Meeting at the CIF/IFC in St. John's. Newfoundland August 3, 1987

August $3,1987$.

3Faculty of Agriculture and Forestry, University of Alberta, Edmonton, T6G 2H1

4 Predicament - an unpleasant, trying, or dangerous situation. fisheries, wildlife, recreation of many kinds, mining, urban growth, rights-of-way, and others necessary to society.

The forestry community may assume and take for granted that an up-do-date and reliable data base is in place. It may also assume that managers and decision-makers are equipped with good policies, strategies and plans. It might be assumed that communication between parties in the forestry community functions in a way that issues are addressed and decisions taken with a fullsome knowledge of both background and the consequences. In sum, it might be assumed that ready information is communicated in a timely fashion and that the system will continue to work to our advantage in the foreseeable future.

\section{The Predicament ${ }^{4}$}

Our contention is that communication in forestry here in Canada is neither serving us well at present, hampering our ability to respond - nor are we equipped to grasp future opportunities to serve the Canadian forestry enterprise in the decades ahead. There are just too many separate and disparate parties. Consider this model of the forestry community (Figure 1). 


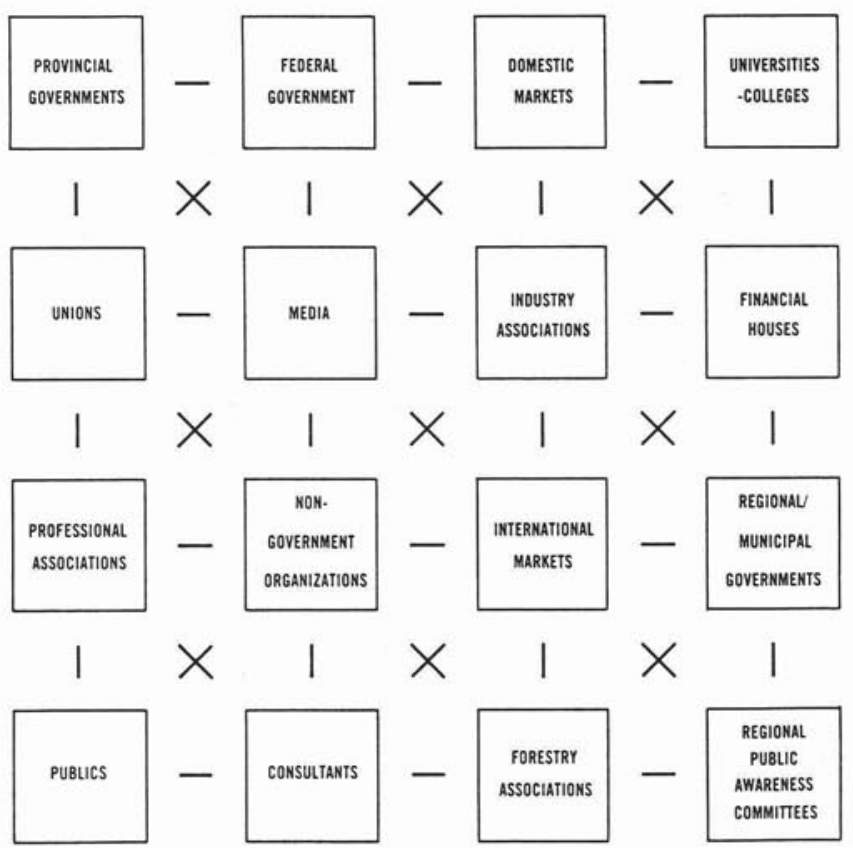

Figure 1. The Canadian Forestry Enterprise.

This model is incomplete but it is intended to show that the Canadian forestry enterprise is large - very large - and very complex. It is made of a large number of stakeholders and participants. There are 43 forest industry associations, five forest product industry unions, eight professional forestry or foresters' associations, four technician or technologists associations, four training and safety associations, eight industry and government research organizations, 10 forest conservation associations, 45 members in The Forestry Constituency, and there are at least 150 non-government organizations with direct interest in forestry matters. ${ }^{5} \mathrm{As}$ well it has extensive linkages between the science, resource management, industry, trade, labor, academic, and public sectors, and all under the governance of law and regulation.

These linkages are numerous and poorly understood by the stakeholders. As a result the Canadian forestry family does not have the benefit of a reliable, up-to-date information base to share among sectors and participants. There are only weak mechanisms for the on-going communication on issues and problems, and effective means for objectively debating options for their solution are lacking. Very few agencies and individuals have the knowledge, skill, mandate and the energy to stay on top of the flux of (Canadian regional, national and international) forestry issues. Consequently the enterprise is poorly equipped to anticipate and do more than react to issues and problems. A consequence of this is that national and regional forestry issues are not easily researched nor are options and solutions made in a way that allows participants in the model to understand broader and longer-term goals and objectives and thereby contribute to concerted action in pursuit of goals.

This predicament is further complicated by the lack of institutions with the mandate and capacity to independently research national forestry issues and alternatives for dealing

5W. Fullerton, President of the Canadian Forestry Association, personal communication. with them. For instance there is no Canadian counterpart to the Resources for the Future Inc. which provides such research and insight into national and regional resource issues in the U.S.A. (It should be noted, however, that national forestry conferences and forums have sometimes served to give periodic and sustained recognition to national problems and solutions.) We need a capacity to collect and maintain regional and national information data bases and to communicate reliable and up-to-date information to users in a timely manner.

No evidence suggests that this predicament will disappear in the foreseeable future. We predict that it will continue to extract a price in the form of imperfect decisions based on incomplete information, a disenchanted public confused by mixed signals from parties responsible for the resolution of chronic (NSR, fire) and new issues (economic timber supply, free-to-grow), conflict between management, labor and government in the creation of goals and objectives beneficial to the enterprise, and other counter-productive developments.

\section{How Can the Predicament Be Ameliorated?}

The model in Figure 1 is intended to show that participants in the model need to share a body of common information, as well as certain broadly defined goals and objectives that address regional and national issues. Current information and effective communications are key elements in this, as well as a mechanism to pull this model together to give it a sense of direction and means for sparking action. Such mechanisms have existed elsewhere and deserve study here (e.g., Australian Forestry Council, Finnish Forestry Association).

We propose that major improvements in communications can be gained by initiatives in two areas, namely in the development of a Canadian forestry network and in the application of communications technology for multi-party information exchange.

\section{Development of the Canadian Forestry Network}

A major impediment is lack of effective communication between participants with common forestry interests. There are two major elements to this impediment: social and technological. There can be no technological fix without the recognition of the need and the will to voluntarily cooperate and to communicate.

The social facet includes our accepting or even the eagerness, to communicate. Elihu Stewart, our first chief forester, realized this full well in 1899 when he reported in 1900:

"recognizing the importance of having the strength of public opinion behind the efforts that were being made to inaugurate and carry out a forestry policy suited to varied conditions of the country, and believing the idea would meet with favour by those who had given the greatest attention to the subject, in January last I took the liberty of inviting a number of gentlemen to meet at my office for the purpose of considering the matter of forming a Forestry Association. This meeting was wellattended by those qualified to express an intelligent opinion on the subject, and the result of their deliberations was the unanimous adoption of a resolution that steps be taken to form a Canadian 
Forestry Association. It is exceedingly gratifying to observe the interest that this moment seems to have awakened in all parts of the country ... Of course the Association has no official connection with any branch of the government service, but it is believed that the deliberations and advice of such a body of men will be of great assistance to this branch in its efforts to inaugurate and carry out a judicious system of forestry in Canada...."

We appear to have re-learned this valuable lesson in the last decade, and there are many heartening signs of a coalescence of like-minded individuals and groups to communicate and act for common purposes. The list is impressive, and some of the most notable are worth specific mention:

(a) One of the quietest and longest-standing, after the Canadian Forestry Association and Canadian Institute of Forestry, has been the Canadian Committee on Forest Fire Management, which was brought together by the National Research Council in 1952 to advise on fire research. This group, representing provincial and federal fire management agencies and educational institutions, provided a forum within which the common ground of the participants became more clearly recognized and opportunities for cooperative action made more apparent. The off-shoot of this process is the Canadian Interagency Forest Fire Centre which is cooperatively funded by all participants to provide both services and advice on a national basis.

(b) In 1970 the Science Council of Canada got the forestry deans together to suggest that they had some common problems that could be more readily solved through group consultation and action. The result was the Association of University Forestry School of Canada (AUFSC) which has emerged as a strong voice in support of education and research, contributing substantially to national debates.

(c) More recently, the provincial professional foresters associations joined with the Canadian Institute of Forestry to form the Canadian Federation of Professional Foresters Associations (CFPFA), now comprising six representative groups. It has entered into a cooperative agreement with the AUFSC to explore the possibilities of a national accreditation scheme for forestry schools which, in turn, should lead to further strengthening of educational programs and reciprocity among provincial associations.

(d) One of the positive results of the first countervail action was to bring Canadian forest industry together on a broader and more determined basis than ever before. The Canadian Forest Industries Council (CFIC) has demonstrated a capacity for cooperative action among otherwise competitors in recognition of common problems.

(e) The Forest Sector Advisory Council combined two previous national committees dealing respectively with timber supply and forest industry. This new group reports jointly to two federal ministers: the Minister of Regional Industrial Expansion and the Minister of State (Forestry and Mines). Members representing the spectrum from timber supply through manufacture and marketing embrace a broad spectrum of the sector and the Council holds great promise as an effective advisory group. (f) The Canadian Council of Forestry Ministers (CCFM) separated itself from the old Canadian Council of Resource and Environment Ministers (CCREM) to allow the provincial and federal ministers to deal more specifically and effectively with the forestry sector. The five national Forestry Forums and the Green Gold/L'Or Vert public awareness program are excellent examples of joint federal/provincial action under CCFM sponsorship.

(g) The first group was the Canadian Forestry Association, established in 1900, and it has maintained a positive influence. The CFA was the catalyst for the National Forest Congress of 1986, and it has been working closely with the CCFM in developing the process to define a national forest sector strategy.

This evolving coalescence of concerned groups for cooperation is an important process. It will be incumbent upon us all to assist the process where possible in establishing further links. The Finnish Forestry Association, for example, has evolved to act on behalf of over a hundred forest resource-related groups and associations. This may or may not be an appropriate model for Canada, but it suggests the possibilities resulting from extended voluntary cooperation and communication.

\section{Application of Communication Technology}

As we extend our voluntary linkages we must also look at the technological possibilities for enhancing communication and cooperative action. There is no quick technological fix, but it can certainly play an important complementary and enabling role. We contend that with rapid advances in computer science, particularly in communications technology for multi-party information exchange, including computer conferencing, the technology exists to accomplish the following:

1. Assemble, stabilize, and disseminate the information base.

2. Identify and position participants with mandates and shared interests.

3. Establish workable linkages between the information base and the managers and decision makers, including "hotlines" to deal with critical and time-dependent issues.

4. Establish and maintain an efficient system of communication on a cost-shared basis.

5. Maintain a file of case studies for evaluation and instructional purposes.

One approach to multi-party conferencing is the CosyComputer Conferencing System which permits many "attendees" at an electronic conference to read all messages that have been sent by any of them, similar to paper messages on a traditional bulletin board (Fig. 2). A computer conferencing system is a powerful and effective means of communication. It can be seen as something half-way between a face-to-face meeting and a very rapidly published newsletter. The system can be used by hundreds of people at diverse locations, and offers a way to share ideas and information that are time and location dependent (COSY Systems Group, 1986).

Conferencing systems must be easy to use for the individual who does not have much experience with computers but, at the same time, offer sophisticated facilities to the advanced user. Each participant must have access to either a computer terminal or a micro-computer with com- 

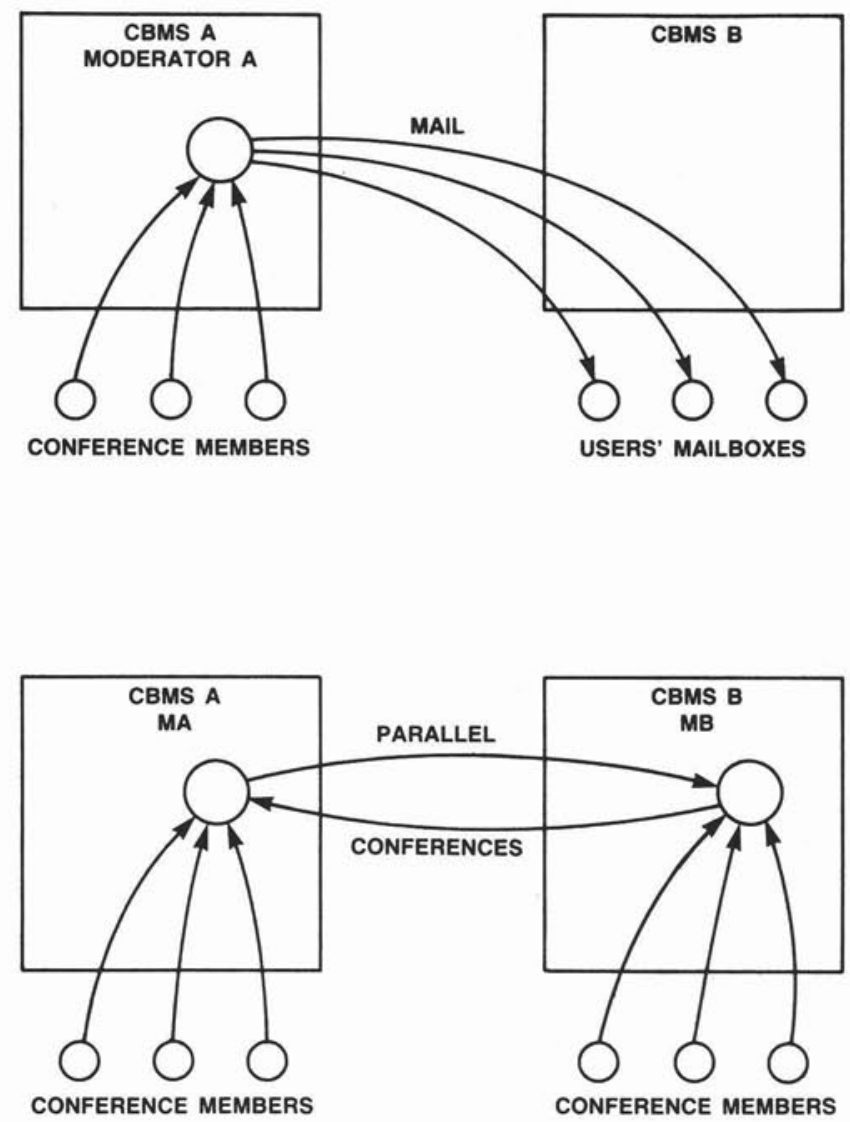

Figure 2. Computer Conference Formats (After Palme, 1985b).

munications software, and must have equipment (i.e., a modem) that lets computers "talk" across telephone lines.

Participants in a computer conferencing system first "log on" to the system, identifying themselves to the system, and then are free to use all the facilities that the system provides. They might choose to send or read private mail messages, or look at conferences that are of interest. The actual text of the message is stored on a computer at the conferencing system headquarters which is, in fact, a database managed as an independent service.

Members can read all the contents of a conference of which they are members, adding their contributions whenever they choose. The conferencing system "remembers" which messages the participant has already seen. When users connect to the system, they receive only their new mail, and usually read only the entries in the conference to which they belong.

The up-front operating costs (exclusive of hardware) are minimal, being in the order of $\$ 50-100$ per month per user group.

Electronic conferencing has advantages over electronic mail, according to Palme (1985a):

1. Computer conferences can function as good electronic mail systems, handling all but the most sensitive correspondence.
2. With conferencing there are better facilities for information control and messages can easily be linked and searched. A participant is not the victim of being a member of many Iong electronic distribution lists.

3. Such conferences are well suited for group communication even over large physical or organizational distances.

We have sketched an encouraging social evolution in forestry in which we are becoming increasingly aware of our interdependence, connections, and need for group activity and have also outlined possibilities for technological linkages to assist the process. The question becomes one of how to begin. We suggest that we start where we can.

At the provincial level, where forestry practice itself is controlled, we have already seen some promising attempts at cooperative action, such as the "Green Machine" in British Columbia, and Silvicon in New Brunswick. In Alberta, the CIF, Alberta Forestry Association, Alberta Forest Products Association, and professional foresters are exploring a coordinating mechanism to enhance group action on common concerns. Perhaps it is within the provinces that the initial focus should be made on networking through a combination of electronic conferencing, telephone linkages and local mailings. The more background we can give to local forestry practitioners, and the more we can make them aware of issues, the better we shall be able to appropriately respond to carry the forestry message. The use of joint meetings should also enhance opportunities for developing forums for debate of the options available and the development of consensus recommendations.

On the national scale, only recently have we come to recognize the importance of national action - as Elihu Stewart did in 1900. Not only is it important to reach federal Members of Parliament, as outlined by Murphy (1987), along with the complexity of federal agencies, but we must also interact with national institutions and develop inter-provincial support.

We recommend that the first step is to identify, describe and develop the regional and national network of co-operating associations and agencies including the Canadian Institute of Forestry, The Canadian Forestry Association with its provincial affiliates, the Canadian Federation of Professional Foresters Associations and the Forestry Constituency. The purpose here is to firm up the provision of vital and timely information and the taking of action on issues by members affected.

With such a network, the next step is the development of an "electronic information hot-line" or action network emanating from a consortium of the groups to speed the information flow to the stakeholders. It should provide a network for quick debate on issues that demand short response times, and enable a call for specific action in response to specific issues.

We conclude that the communications predicament can be addressed with a two-step networking and electronic communications venture. The situation calls for a fairly longterm commitment to the improvement of information exchange. The enterprise is too large for a quick fix. But technology is on our side and at present the solutions seem to be available. 


\section{References}

COSY Systems Group. 1986. COSY Computer Conferencing System Reference Manual. Univ. Guelph, Guelph, Ontario. 72 pp.

Licker, P.S., P.R. Newsted and B.S. Sheehan. 1986. A value-added model of electronic mail utilization. Proc. Pacific Telecommunications Council Meeting. Fac. Manage. Univ. Calgary, Alberta, $10 \mathrm{pp}$.

Murphy, P.J. 1987. Informing Members of Parliament about the forestry sector: results of a questionnaire survey. Fac. Agric. and For. Univ. Alberta. 10 pp. In preparation.

Newsted, P.R. 1987. Managing an information systems area using an electronic conference. Proc. ASAC Conf. Toronto, Ontario. Fac. Manage., Univ. Calgary, Alberta. 8 pp.
Newsted, P.R. and P.S. Licker. 1987. A value-added model of computer aided communication. Proc. Sympo. on Computer Conferencing and Allied Technologies. Fac. Manage. Univ. Calgary, Alberta. $11 \mathrm{pp}$.

Palme, J. 1985a. Computer conferencing: more than electronic mail. Proc. Computer Conferencing and Electronic Messaging Conference. Guelph, Ontario. pp. 3-10.

Palme, J. 1985b. Conferencing standards. BYTE. Dec. 1985. pp. 187191

Sheehan, B.S. and P.R. Newsted. 1986. Telematic Services of the Canadian Higher Education Research Network. Proc. Conf. on Communications Technology in Higher Education. Fac. Manage Univ. Calgary, Alberta. $18 \mathrm{pp}$

Stewart, E. 1899. Annual report of the Superintendent of Forestry. Sessional Papers A 1900. Dept. Interior, Ottawa.

\section{Membership Dues 1988-1989}

\section{National \\ Dues}

\author{
Active Membership \\ 1 st and 2 nd year after graduation \\ grad 1987, grad 1986) \\ Other new Active Members 1st year \\ Married or equivalent, second member only \\ All other Active Members

\section{Affiliate Membership} \\ 1 st and 2nd year after graduation \\ (grad 1987, grad 1986) \\ Other new Affiliate Members 1st year \\ Married or equivalent, second member only \\ All other Affiliate Members \\ Members with Retired Status receiving \\ The Forestry Chronicle \\ Members with Retired Status not receiving \\ The Forestry Chronicle \\ Student Members \\ Sustaining Members (CIF) \\ Sustaining Members (Other)
}

\section{Section Dues}

$\$ 70.00$

$\$ 70.00$

$\$ 70.00$

$\$ 98.00$

$\mathrm{AL} \$ 8.00$

CC $\$ 8.00$

$\mathrm{CH} \$ 8.00$

CO $\$ 10.00$

CR $\$ 8.00$

KO $\$ 10.00$

LW $\$ 13.00$

MB $\$ 7.00$

$\$ 70.00$

$\$ 70.00$

$\$ 92.00$

$\$ 29.00$

$\$ 00.00$

$\$ 29.00$

$\$ 30.00$

$\$ 200.00$
NW $\$ 10.00$

OK $\$ 5.00$

OR $\$ 5.00$

OV $\$ 8.00$

PA $\$ 8.00$

RM $\$ 10.00$

SK $\$ 10.00$

SN $\$ 8.00$

SO $\$ 15.00$

VA $\$ 10.00$

VI $\$ 5.00$

The Institute year runs from July 1 to June 30 . Applications dated after January 1 will be charged half dues for that Institute year. Applications dated after April 1 will be charged no dues for that Institute year.

Section dues are in addition and range from $\$ 5.00$ to $\$ 20.00$. 